\title{
Is lung ultrasonography really useful for diagnosing weaning-induced pulmonary oedema?
}

\author{
Satoshi Yamaga, Shinichiro Ohshimo *i) and Nobuaki Shime
}

(c) 2019 Springer-Verlag GmbH Germany, part of Springer Nature

\section{Dear Editor,}

We would like to discuss several factors potentially affecting the results of lung ultrasonography when used to diagnose weaning-induced pulmonary oedema (WIPO), as described in a recent issue of Intensive Care Medicine [1].

First, although the authors showed no significant differences in the baseline characteristics between patients with and without WIPO, several potential factors associated with WIPO were lacking in the discussion. The authors observed more B-lines before a spontaneous breathing trial (SBT) $(5 \pm 5$ vs. $3 \pm 3, P=0.01)$ in the WIPO patients than in those without WIPO, suggesting higher hydrostatic pressure in the WIPO group. It would have been helpful to have a plausible explanation for this difference (e.g., a positive fluid balance could be a risk factor for weaning failure [2]). Moreover, pre-SBT ventilator settings, especially those of positive end-expiratory pressure, could have affected a changing breathing workload and intrathoracic pressure during SBT [3].

Second, we wish the authors had provided data concerning the treatment, including diuretics, during the SBT trial. It is of great interest whether such weaning failures were potentially treatable.

Finally, it is questionable whether it is indeed easy and reproducible to accurately determine that B-lines in WIPO patients are increased. Multiple B-lines could move rapidly with lung sliding signs due to tachypnoea, which might have caused large variation in the number of B-lines, according to the operators. Although it may be easy and non-invasive to perform lung ultrasonography, the reproducibility of B-line detection among operators requires discussion.

\section{Funding}

This work was supported by KAKENHI Grants from the Japan Society for the Promotion of Science (JP 17K11573), and the Strategic Information and Communications R\&D Promotion Programme, and the Japan Agency for Medical Research and Development.

\section{Compliance with ethical standards}

Conflicts of interest

The authors have no potential conflicts of interest to declare.

\section{Publisher's Note}

Springer Nature remains neutral with regard to jurisdictional claims in published maps and institutional affiliations.

Accepted: 30 May 2019

Published online: 6 June 2019

\section{References}

1. Ferré A, Guillot M, Lichtenstein D et al (2019) Lung ultrasound allows the diagnosis of weaning-induced pulmonary oedema. Intensive Care Med 45:601-608. https://doi.org/10.1007/s00134-019-05573-6

2. Upadya A, Tilluckdharry L, Muralidharan V et al (2005) Fluid balance and weaning outcomes. Intensive Care Med 31:1643-1647. https://doi. org/10.1007/s00134-005-2801-3

3. Cabello B, Thille AW, Roche-Campo F et al (2010) Physiological comparison of three spontaneous breathing trials in difficult-to-wean patients. Intensive Care Med 36:1171-1179. https://doi.org/10.1007/s0013 4-010-1870-0

\footnotetext{
*Correspondence: ohshimos@hiroshima-u.ac.jp

Department of Emergency and Critical Care Medicine, Graduate School of Biomedical and Health Sciences, Hiroshima University, 1-2-3 Kasumi, Minami, Hiroshima 734-8551, Japan
}

\section{Springer}

